\title{
27. EL ESTATUTO JURÍDICO DE LOS MIEMBROS DEL GOBIERNO (Arts. 98.3 y 4)
}

\author{
PEDRO J. HERNANDO GARCÍA \\ Profesor de Derecho Constitucional \\ Universidad de Cantabria
}




\section{SUMARIO}

I. Preliminar.-II. El estatuto de los miembros del Gobierno en el DeRECHO COMPARADO.-III. REgULACIÓN JURIDICO-CONSTITUCIONAL EN EL SISTEMA ESPAÑOL.-A. La compatibilidad con el mandato parlamentario. B. Incompatibilidad con el ejercicio de cualquier función pública. C. Incompatibilidad con cualquier actividad profesional o mercantil. IV. CONCLUSIÓN. 


\section{EL ESTATUTO JURÍDICO \\ DE LOS MIEMBROS DEL GOBIERNO \\ (Arts. 98.3 y 4)}

POR

PEDRO J. HERNANDO GARCÍA

Profesor de Derecho Constitucional

Universidad de Cantabria

\section{PRELIMINAR}

Los aspectos referentes al status jurídico de los miembros del Gobierno se recogen en el texto constitucional de 1978, estableciendo, por un lado, una serie de incompatibilidades específicamente detalladas y así, el art. 98.3 señala que,

«Los miembros del Gobierno no podrán ejercer otras funciones representativas que las propias del mandato parlamentario, ni cualquier otra función pública que no derive de su cargo, ni actividad profesional o mercantil alguna"

y por otro, mediante una remisión a un desarrollo legal posterior que "regulará el estatuto e incompatibilidades" de una manera particular, tal y como recoge el punto cuarto de dicho artículo 98.

La razón de la falta de sistemática del 98.4 al separar estatuto e incompatibilidades, podemos encontrarla en la tradición legislativa de nuestro constitucionalismo, que ha diferenciado lo que son normas relativas al "estatuto juridico" de los miembros del Gobierno, de lo que son propiamente las incompatibilidades. La regulación de éstas, se ha plasmado no 
sólo en los preceptos dedicados al Gobierno sino también, en lo que abordan el estatuto de los parlamentarios, condición que, como veremos, ha sido tradicionalmente compatible con el ejercicio de la función ejecutiva como miembros del Gobierno

Por tanto, si bien es cierto que ha existido esa diferenciación a efectos de sistemática constitucional en la regulación de las citadas materias, no lo es menos que las incompatibilidades son una parte integrante del estatuto jurídico general junto con las prerrogativas, el fuero procesal especial, el régimen económico, etc., y que por esa misma razón, bien se podria simplificar la redacción constitucional reconduciendo los contenidos de las incompatibilidades al genérico de "estatuto de los miembros del Gobierno" por las razones que más adelante se expondrán. Las citadas son simplemente cuestiones de sistemática y por ello no merecen, en este momento, un análisis más detallado.

\section{EL ESTATUTO DE LOS MIEMBROS DEL GOBIERNO EN EL DERECHO COMPARADO}

Conviene, antes de comenzar el análisis del contenido de los citados preceptos, y de buscar soluciones para su mejora, realizar primeramente un somero estudio en torno a la regulación constitucional del estatuto de los miembros del Gobierno en el derecho comparado. No es el momento de entrar a diferenciar, como luego haremos, los sistemas según su forma de Gobierno, lo que influirá claramente en la regulación de estas materias, especialmente en lo que respecta a la compatibilidad del cargo con el mandato parlamentario. Sin embargo, creo interesante reflejar las diversas formas en que las Constituciones de los países de nuestro entorno se ocupan del tema.

Comenzando por la regulación de la compatibilidad del ejercicio con el mandato parlamentario, podemos encontrar, por un lado, constituciones que recogen tal posibilidad expresamente, como la Constitución belga, que en su artículo 88 señala que "los Ministros sólo tendrán voto en una u otra Cámara si fueren miembros de la misma" y además el art. 56 bis $1 .^{\circ}$, al establecer las condiciones para ser elegido senador, se refiere explícitamente a los Ministros, reafirmando esta posible compatibilidad ',

1 El artículo 56 bis. señala que "para poder ser elegido senador por aplicación de lo dispuesto en el aptdo. $1 .^{\circ}$ del art.53 hay que pertenecer además, a una de las categorías siguientes: $\left.10^{\circ}\right)$ Ministros, Ex-Ministros y Ministros de Estado". 
o como la irlandesa que convierte la condición de diputado de la Cámara de Representantes en requisito imprescindible para ser elegido Presidente, Vicepresidente o Ministro de Hacienda y asimismo consagra la necesidad de ser diputado o senador para formar parte del Gobierno, con una limitación para estos últimos ${ }^{2}$.

Por otro lado, algunos textos recogen la situación contraria. Así el artículo 23 de la Constitución de la V República francesa o el precepto 70.2 de la Constitución austríaca que recoge una fórmula por la cual "Sólo podrá ser designado Canciller Federal, Vicecanciller o Ministro Federal quien sea elegible al Consejo Nacional. No podrán, sin embargo, los miembros del Gobierno Federal pertenecer al Consejo Nacional". También en este sentido, la Constitución Federal de la Confederación Helvética en su artículo 101 admite la participación en las sesiones de los miembros del Consejo Federal pero sin derecho de voto. Finalmente, en torno a esta compatibilidad, es interesante citar la regulación de la Constitución holandesa. Ésta, en la Sección cuarta de su Capítulo III "De los Estados Generales", contiene un artículo, el 104, de características similares al anteriormente citado artículo 101 de la Confederación Suiza. Pero, a renglón seguido, el párrafo segundo del art. 106 (que en principio prohibe el ejercicio simultáneo de las funciones de Ministro, Vicepresidente o miembros del Consejo de Estado, con la pertenencia a los Estados Generales) admite la posibilidad de que los Ministros se presenten a las elecciones y si son elegidos acumular durante un máximo de tres meses el ejercicio de sus funciones como Ministro y la pertenencia a los Estados Generales. Es, pues, una prohibición pero con una clara excepción que, como tal, no existe en ningún otro texto.

Dejando de lado esta relación actividad parlamentaria-función ejecutiva, sobre la que luego se entrará más en profundidad, por lo que se refiere a la plasmación constitucional de las incompatibilidades pública y privadas de los miembros del Gobierno también existen divergencias entre las diferentes regulaciones.

En Alemania, el artículo 55 reconoce la incompatibilidad tanto para el ejercicio de función pública como privada a los Ministros y al Canciller

2 La regulación constitucional irlandesa de esta materia, se encuentra en su art.28.7 cuyo primer punto se refiere a que "El Taoiseach, el Tanaiste y el miembro del Gobierno que tenga a su cargo el Ministerio de Hacienda, deberán ser diputados de la Cámara de Representantes" y su punto $2 .^{\circ}$ " "Los demás miembros del Gobierno deberán serlo de la Cámara de Representantes o del Senado, si bien no podrán ser senadores más de dos en total." Este texto es, como se observa claramente, la plasmación jurídico-constitucional de la práctica inglesa en materia de nombramientos ministeriales. 
Federal. También el artículo 97 de la Constitución suiza y el 9 del Capítulo 6 de la sueca lo reconocen explícitamente ${ }^{3}$. Otros textos no sólo hacen expresa mención sino que además se remiten a la necesaria regulación por ley posterior. Así, por ejemplo, el artículo 81.3 y 4 de la Constitución griega, al regular que «la ley podrá establecer las incompatibilidades de la cualidad de Ministro y de Secretario de Estado con otras actividades".

Finalmente, cabe hacer referencia a dos textos especialmente interesantes por la regulación que hacen de esta materia. Por un lado, la Ley Constitucional de Finlandia que si bien no establece unas incompatibilidades expresas, sí se refiere a que los miembros del Consejo de Estado serán nombrados de entre personas conocidas upor su honradez y competencia». Se establece además el requisito de la licenciatura en derecho para poder ser ministro de Justicia y además otro de los miembros deberá poseer estos mismos conocimientos (art.37). No es, ciertamente, una incompatibilidad, pero no deja de suponer una expectativa constitucional encaminada a preservar la independencia y el correcto ejercicio de las funciones de los miembros del poder ejecutivo.

Por su parte, la Constitución holandesa, anteriormente citada, en el párrafo 7 del artículo 86 , incorpora una previsión que podríamos denominar juramento de honestidad o de incorruptibilidad, y que en términos constitucionales es el van zuivering o promesa de purificación. Por tanto, antes de jurar su cargo como Ministros, deben declarar o jurar: "...que para ser nombrado Ministro no he dado ni prometido directa o indirectamente a nadie regalo ni presente alguno, bajo ningún título o pretexto de cualquier indole" y "...que no aceptaré de nadie en absoluto, directa o indirectamente, promesa o presente por hacer o consentir algo en el ejercicio de mi cargo". Tampoco fija este precepto unas incompatibilidades claramente delimitadas, pero en cambio crea en torno a las personas que ocupan estos cargos, una imagen de honestidad y de independencia que debe servir de ejemplo para la actuación de toda la clase política del país.

3 "No podrán los miembros del Consejo Federal durante el período de su mandato desempeñar ningún otro empleo al servicio dela Confederación ni ejercer otra carrera o profesión" (Art. 97 Constitución suiza) y de similar carácter la regulación sueca "Ningún miembro del Gobierno podrá ejercer función pública ni privada, ni asumir misión o desempeñar actividad susceptible de dañar la confianza depositada en él» (art. 9 párrf. 2. ${ }^{\circ}$, Capít. 6, de la Constitución sueca) 


\section{REGULACIÓN JURIDICO-CONSTITUCIONAL EN EL SISTEMA ESPAÑOL}

Analizado, pues, someramente el panorama constitucional comparado, y conocidas las diferentes maneras en que se regula el estatuto de los miembros del Gobierno, se hace necesario entrar a analizar las previsiones contenidas en nuestro texto constitucional. A la vista de la actual redacción y teniendo como objetivo buscar, si se justifica adecuadamente, una reforma de su contenido material, $y$ no sólo un perfeccionamiento formal, para adecuarlo a la realidad socio-política actual, hay que comenzar desglosando adecuadamente los distintos contenidos que recoge el citado precepto, pudiendo distinguir: $A$. La compatibilidad con el mandato parlamentario, excluyendo, sin embargo, el ejercicio de todos los demás cargos de elección popular (alcaldías, escaños de Parlamentos autonómicos, etc.); $B$. La incompatibilidad con el ejercicio de cualquier otra función pública, con la salvedad lógica de aquellas que deriven directamente el ejercicio de su cargo; y finalmente, $C$. Un tercer bloque que abarcaría la incompatibilidad con el ejercicio de cualquier actividad privada de carácter profesional, mercantil, etc.

\section{A. La compatibilidad con el mandato parlamentario}

La posibilidad de compatibilidad el mandato parlamentario con las funciones propias de miembro del Gobierno, es uno de los elementos caracterizadores del sistema parlamentario, siendo incluso para algunos autores un dato indeleblemente unido a la definición de éste. La posibilidad de pertenecer simultáneamente al Gobierno, como encarnación del poder ejecutivo $y$ al Parlamento como poder legislativo, es también una de las fundamentales diferencias entre los sistemas de gobierno presidencialistas o semipresidencialistas y los sistemas parlamentarios. Así, el artículo $1 .^{\circ}$, Sección $6 .^{a}$ párrf. $2 .^{\circ}$ de la Constitución de los Estados Unidos de América excluye tal posibilidad pues uninguna persona que ocupe este cargo en los Estados Unidos (senador o representante) podrá formar parte de cualquiera de las Cámaras mientras continúe en funciones». Se observa la absoluta separación existente entre el desempeño de la función ejecutiva y el ejercicio del cargo representativo. En este sentido se expresa también la Constitución francesa de 1958 en su art. 23 ( LLas funciones de miembros del Gobierno son incompatibles con el ejercicio de todo mandato parlamentario») y el artículo 157.2 de la Constitución portuguesa de 1976 ("Los diputados que fueren nombrados miembros del Gobierno no podrán ejercer el mandato mientras no cesen en dicha función»). 
Frente a la absoluta incompatibilidad reconocida en los sistemas presidencialistas, la Constitución española de 1978 recoge en su articulado los principios del sistema parlamentario, siguiendo una línea marcada por nuestra tradición histórico-constitucional y por el constitucionalismo comparado. Si exceptuamos la Constitución de 1812, que prohibía expresamente la elección de los Secretarios de Estado como diputados, y la Constitución Republicana de 1873, que introduce un sistema presidencialista y determina por ello la clara separación del ejercicio de las funciones legislativas y ejecutivas ${ }^{4}$, la historia constitucional española, a lo largo de todos sus textos, ha reconocido específicamente esta posibilidad de compatibilizar ambas funciones. El Estatuto Real de 1834, en su art. 3.4, reconoce expresamente la posibilidad de que los Secretarios de Despacho en activo perteneciesen al estamento de Próceres del Reino, si bien no se hace referencia alguna a la posibilidad de pertenencia de éstos al cuerpo de Procuradores o Cámara Alta ${ }^{5}$. También admiten esta posibilidad, la Ley de noviembre de 1836; la Constitución de 1837, que en su artículo 62 establece una formulación de la compatibilidad que se va a repetir posteriormente a lo largo de todo el constitucionalismo español ("Los Ministros pueden ser senadores o diputados y tomar parte en las discusiones de ambos Cuerpos Colegiados; pero solo tendrán voto en aquel al que pertenezcan"); las Constituciones de 1845 (art. 65), 1856 (art. 66), 1869 (art. 88, con ligeras matizaciones ${ }^{6}, 1876$ (art. 58) y la Constitución de la 2. ${ }^{a}$ República Española de 1931.

4 La Constitución gaditana de 1812 excluía en su artículo 95 de manera expresa la compatibilidad al referirse a que "los Secretarios de Despacho, los consejeros de Estado y los que sirven a la Casa Real, no podrán ser elegidos diputados a Cortes». En este mismo sentido el artículo 65 de la Constitución de 1873 afirma que "Los ministros no podrán ser diputados ni senadores ni asistir a las reuniones sino por mandato especial de la Cámara». Esta incompatibilidad se vio desarrollada, si bien de manera limitada a los ministros y por especiales circunstancias del momento histórico, en el R.D. sobre normas electorales de 18 de marzo de 1977 en cuyo preámbulo se decía "...por último y atendiendo a las peculiaridades del aquí y ahora español, se consideran inelegibles los titulares de los cargos que en las más solidas democracias no lo son, pero cuya intervención en estos primeros comicios podría devenir inconvenientemente a los efectos de mejor conocer la voluntad del pueblo español»

5 Esta "laguna» constitucional del Estatuto Real de 1834, al no incluir en su art. 15 la posibilidad de que los Secretarios de Despacho fueran miembros de la Cámara Alta, se corrige en el artículo 107 del Reglamento de 15 de julio de 1834 en el que se reconoce que los ministros tendrán voz pero no voto "salvo que el Secretario de Despacho sea al mismo tiempo Procurador a Cortes" teniendo entonces todos los derechos y prerrogativas inherentes a su cargo representativon.

6 "No podrán asistir a las sesiones de las Cortes los ministros que no pertenezcan a uno de los Cuerpos Colegisladores" (art.88 de la Constitución de 1869). 
Existen igualmente, como hemos visto al comienzo de este trabajo, numerosas referencias en derecho comparado que consagran unos contenidos similares a los del actual artículo 98.3, y cabe citar entre ellas, refiriéndonos a regulaciones constitucionales de dos países con sistemas de diferentes, el art. 64 párrf. $4 .^{\circ}$ de la Constitución italiana (Los miembros del Gobierno, aún cuando no formen parte de las Cámaras, tendrán derecho, y si son convocados, obligación de participar en las sesiones...), y el artículo 101.2 de la Constitución búlgara de 1971 ("También podrán ser miembros del Consejo de Ministros personas que no sean Diputados»).

Es, pues, nuestro actual 98.3 heredero de toda una larga tradición propia y comparada, que ve su plasmación no sólo en el citado precepto sino también y más específicamente en el art.70.1 b) que recoge las incompatibilidades de los Diputados y Senadores, excluyendo expresamente de éstas a "los miembros del Gobierno". Ahora bien, aquí nos encontramos con el problema de delimitación conceptual del Gobierno como órgano constitucional. ${ }^{7}$ Para aplicar debidamente la compatibilidad constitucional es necesario establecer quiénes son específicamente miembros del Gobierno y quiénes no. Por ello, habrá que determinar previamente, en consecuencia con lo anterior, el concepto de Gobierno, entendiéndolo bien en sentido amplio, como órgano que abarcará no sólo la reunión del Presidente, Vicepresidentes y Ministros, sino también "a los demás miembros que por ley se establezcan" o bien en sentido estricto limitando su composición. Delimitado esto, habrá que analizar la pertenencia o no de figuras como los Secretarios de Estado a este concepto restringido y su posibilidad o no de simultanear las labores representativas inherentes a su mandato y las funciones ejecutivas por razón de su cargo en la Administración del Estado.

La figura del Secretario de Estado, creada en España por R.D. 1558/ 1977 de 4 de julio, aparece como un órgano auxiliar de todos los miembros del Gobierno, situándose como "un escalón intermedio entre los Ministros y Subsecretarios". Por esta condición y por sus propias funciones reguladas en dicho decreto, que pueden llegar hasta el ejercicio de actividades propias del Ministro o la asistencia a los Consejos de Ministros, cuando así se les requiera pero sin derecho a participar en las deliberaciones ni a votar (disposición final 1. 2 del RD 1558/1977), se admite, por un sector de la doctrina, su encuadre en el concepto de Gobierno que parece configurarse a la luz de las previsiones del artículo 98 de la Constitución.

La Constitución no define específicamente el Consejo de Ministros

7 V. A. BAR CENDÓN: «Sobre una hipotética reforma del Título IV ("Del Gobierno y de la Administración") de la Constitución de 1987", en esta misma Revista. 
como un órgano del engranaje constitucional y, por tanto, no diferencia lo que se deba considerar Gobierno y lo que sea estrictamente Consejo de Ministros. El problema se plantea, pues, en torno a si debemos entender en términos jurídicos el concepto constitucional en sentido estricto o sentido amplio, con las consecuencias que en cada caso conllevaría. El artículo 98.1 al referirse a la composición del Gobierno habla de las figuras del Presidente, del Vicepresidente, de los Ministros y de "...los demás miembros que establezca la ley", dentro de los cuales podríamos encuadrar la figura de los Secretarios de Estado. Tras la publicación de la LOACE (L.10/83 de 10 de agosto) y partiendo de la concepción de la administración central que en ella se recoge, resulta bastante difícil considerar a los Secretarios como verdaderos componentes estructurales del Gobierno en sentido estricto. El artículo 4 de la LOACE $-y$ los arts. 5,6,7,10,11 de la Ley de Régimen Jurídico de la Administración del Estado- omite cualquier referencia a ellos al referirse al Consejo de Ministros como el órgano que reúne como miembros de pleno derecho al Presidente, el Vicepresidente o Vicepresidentes y los Ministros, y el art.12 señala que para su creación, modificación, refundición o supresión sólo será necesario un Real Decreto frente a la obligatoriedad de la reserva de ley que procederá en todos los casos que se quiera modificar, crear o suprimir un Departamento Ministerial (art. 98.1 CE y $11 \mathrm{LOACE}^{8}$. También como apoyo a esta tesis, encaminada a la delimitación del concepto de Consejo de Ministros como una figura constitucional autónoma, excluyendo por tanto de él a los Secretarios de Estado - que sí formarían parte del Gobierno en sentido amplio-, cabe citar lo dispuesto en la Ley $25 / 1983$ de 26 de diciembre, sobre incompatibilidades en el sector público. En su artículo 1.1 se diferencia entre los miembros del Gobierno y los Secretarios de Estado encuadrándolos a los efectos de la Ley como Altos Cargos pero separando su figura de la de los Ministros, el Presidente y los Vicepresidentes, como componentes éstos del órgano específico. La distinción también se refleja en el artículo 4, que recoge la compatibilidad de los miembros del Gobierno con el mandato parlamentario separando, pese a incluirlos en la misma situación excepcional, las figuras de los Ministros y los Secretarios de Estado, dejando claro que éstos no forman parte de aquél. Finalmente, cabe señalar que el artículo 100 de la CE al referirse a que el nombramiento y cese de ulos demás miembros" del Gobierno se hará por el Rey a propuesta del Presidente, se está refiriendo exclusivamente al Vicepresidente y a los Ministros, excluyendo a los Secretarios de Estado como parte integrante del órgano. Así se

8 Vid. E. Álvarez CONDE: El régimen político español (Madrid: Tecnos, 1990), pág. 477. En este sentido la Ley 31/1991 de 30 de diciembre, de Presupuestos Generales del Estado para 1992, prevé en su disposición final tercera la autorización al Presidente del Gobierno "para variar, mediante Real Decreto, dictado a propuesta del mismo el número, denominación y competencias de los Departamentos Ministeriales". 
reafirma jurídicamente en la disposición final 1. 5 del R.D. 1558/1977 y el art.10.7 LRJ en donde se especifica que éstos son designados por Real Decreto aprobado en Consejo de Ministros a propuesta del Ministro correspondiente. Por tanto, no sólo el procedimiento de creación, modificación o supresión es diferente sino también sus funciones e incluso la forma de su nombramiento y cese.

Establecida esta diferencia, cabe preguntarse si tiene sentido que, no siendo miembros del Consejo y entendiendo, que la posible reforma de este artículo 98 debiera ir en la vía de acotar el concepto de Gobïerno, posibilitando la creación de un órgano diferenciado al que denominaríamos Consejo de Ministros, los Secretarios de Estado deban estar exentos de la incompatibilidad con el ejercicio del mandato representativo. El art. 70.1.b) de la CE se refiere a los miembros del Gobierno, término que deberiamos entender como "miembros del Consejo de Ministros" y por tanto la previsión del artículo 4 de la Ley de Incompatibilidades de Altos Cargos debería ser modificada excluyendo la figura de los Secretarios de Estado de tal excepción. Es lógico pensar que la función de los Secretarios de Estado es de mayor contenido de dirección administrativa que la que realiza propiamente un Ministro, al cual además está ligado orgánicamente, y por ello no sería adecuada su participación en los órganos legislativos del Estado, de la misma manera que se prevé para el resto de los Altos Cargos de la Administración del Estado en el art.70.1. b) de la CE y los arts. 6.1. f) y 157.3 de la LOREG. La necesaria separación de funciones (arts. 66.2, 97 y 117.3 de la Constitución), y dedicación absoluta a ellas sirven como fundamento, entre otras que sería demasiado extenso enumerar, a esta posible matización del texto constitucional.

Un segundo problema que se plantea a la luz de la redacción constitucional es si el mandato parlamentario, al que se refiere el 98.3, ha de circunscribirse únicamente a las Cortes Generales o si se puede ampliar el concepto a los Parlamentos Territoriales de las Comunidades Autónomas. La solución nos ha venido dada por la redacción del artículo 4 de la Ley $25 / 1983$ que lo limita exclusivamente a las funciones representativas inherentes a los cargos de Senador y Diputado de las Cortes Generales, quedando excluida cualquier otra posibilidad de ejercicio de cargos electivos de carácter autonómico. Esto es lógico ya que dada la estructura territorial del Estado español se hace necesaria una clara diferenciación,entre las personalidades y las funciones de los interlocutores autonómicos y las propias del Gobierno central.

Una tercera cuestión giraría en torno a la práctica de otros sistemas constitucionales, como el francés, en el que cabe el ejercicio de funciones de Gobierno y su simultaneidad con la detentación de alcaldías u otros cargos representativos menores. En nuestro país esta solución resulta ina- 
decuada a la luz del modelo territorial surgido de la Constitución de 1978, dadas las diferencias con el modelo francés en el que, en palabras de MORELL OCAÑA, la situación es explicable debido a la intensa centralización por lo que uresulta extremadamente conveniente tener un valedor de altura ante los propios servicios centrales del Estado".

\section{B. Incompatibilidad con el ejercicio de cualquier función pública}

Esta incompatibilidad constitucional tiene su antecedente legal directo en el artículo 86.1 de la Ley de Funcionarios Civiles del Estado de 1974, en el que se señala que no se podrán desempeñar simultáneamente varias plazas en los cuerpos de la Administración y se verá reforzado en la Ley $26 / 1983$ cuyo artículo $2 .^{\circ}$ recoge la necesaria dedicación absoluta de los cargos a los que se aplica esta Ley -entre ellos, por tanto, a los miembros del Consejo de Ministros-y que en su art. $3 .^{\circ}$ detalla de las actividades públicas que no podrán ser desarrolladas por éstos. Las razones de esta limitación, también existente en las legislaciones constitucionales de otros países ${ }^{9}$, se derivan de la necesidad de una completa dedicación a sus funciones que conllevará el buen funcionamiento de todo el organigrama político-administrativo y el evitar la acumulación indebida de cargos y funciones en número reducido de personas que perjudicaría los objetivos y la funcionalidad de su actuación.

\section{Incompatibilidad con cualquier actividad profesional o mercantil}

La discusión de los contenidos del actual 98.3 y 4 a lo largo del proceso de redacción constitucional no tuvieron apenas relevancia y por ello no se ha hecho necesaria su referencia hasta este momento. Pero si hubo en aquellos momentos alguna discusión sobre los mismos, ésta fue en torno a la inclusión del término "mercantil» en él, en aquellos momentos, artículo 92 y actual 98.3 del texto constitucional. El problema, llevado a discusión por el senador Ollero Gómez, fue que, en su opinión, incluir el término "mercantil", de claros contenidos económicos, llevaria a una posible interpretación extrema del concepto, que podía dar lugar a entender como incompatibles actividades como "...operar en bolsa, mantener una cuenta corriente bancaria..." y por ello propuso su eliminación por entenderlo

$9 \quad$ V. pág. 38 y ss de este trabajo. 
comprendido en "actividad profesional" o, en su defecto, la sustitución por "ejercicio del comercio». La enmienda fue desestimada y la redacción quedo tal y como hoy la conocemos ${ }^{10}$.

Por tanto todas las fuerzas políticas estuvieron de acuerdo en esta inclusión de la incompatibilidad profesional y mercantil y así en la legislación posterior, la exposición de motivos de la ley 25/1983, recoge una justificación de la misma aduciendo la necesidad de garantizar la independencia e imparcialidad de los Altos Cargos pero también el evitar la colisión de intereses particulares y públicos y la especial dedicación que han de tener las personas en ellos destinados.

Estas mismas incompatibilidades con el ejercicio de cualquier otra función o actividad privada se recogen en numerosos textos constitucionales como los ya citados artículos 23 de la Constitución francesa y 66 de la alemana de 1949 .

El desarrollo legal post-constitucional de esta materia se realiza en la citada Ley 25/83 que afirma que «el ejercicio del cargo se desarrollará con dedicación absoluta, siendo incompatible con el desempeño por sí o mediante sustitución de cualquier otro puesto o actividad, públicos o privados, por cuenta propia o ajena,...". Por lo que se refiere a los ámbitos de incompatibilidad en particular, se incluyen en el artículo 7 quedando fuera de ellos la administración del patrimonio personal y familiar dentro de determinadas condiciones (art.8).

Admitiendo como necesaria esta incompatibilidad y su plasmación constitucional, con el fin de asegurar la ejemplaridad de las actuaciones de los gobernantes ante la opinión pública, cabe plantearse los términos de la misma, ya que quizás dados los niveles de falta de moralidad en algunos sectores de la vida pública, pudiese ser conveniente en aras de un mayor solidaridad y ejemplaridad la prolongación de ésta durante un período posterior al propio del ejercicio del cargo. En este sentido existen antecedentes en nuestra propia legislación, como el R.D. $2413 / 1928$ de 23 de diciembre, la Ley de 8 de abril de 1933 o el propio Decreto Ley de 13 de mayo de $1955^{11}$. Es por tanto una posibilidad que no se puede desestimar

10 Trabajos Parlamentarios. Constitución española, vol.Ill, págs. 2443 y ss. Edit. Cortes Generales, 1989.

11 El art. 3 párrafos finales de la ley de 8 de abril de 1933 entendía que los que hubiesen sido Ministros o Subsecretarios no podrian obtener hasta dos años después del cese de su cargo ninguno de los puestos que se detallaban en dicha ley (cargos dependientes de la Administración o relacionados con ella), salvo que mediase una designación expresa. También se recogía la incompatibilidad durante los dos años posteriores al cese de la actividad de abogado con el ejercicio anterior 
y que podria reflejarse en la legislación que desarrolle los contenidos del precepto constitucional siguiendo la línea iniciada por el R.D. 2102/1983 de 4 de agosto, que regula es estatuto de los ex-Presidentes del Gobierno ${ }^{12}$, extendiendo una serie de medidas de asistencia hasta cuatro años después de su cese. Esta situación podría fundamentar, a sensu contrario, la posibilidad de extensión de las incompatibilidades afectas al cargo por el mismo período de tiempo.

\section{CONCLUSIÓN}

Siguiendo el razonamiento hasta ahora expuesto, y partiendo de la diferenciación entre los conceptos Gobierno y Consejo de Ministros; admitiendo como necesaria la compatibilidad de las funciones de los miembros del Consejo con el mandato representativo, entre otras razones señaladas, con el fin de evitar el distanciamiento entre el poder ejecutivo y la propia sociedad representada en el Parlamento; admitiendo, asimismo, la necesidad de que exista una plasmación constitucional del elenco de actividades de incompatible realización para éstos, al igual que existe para los miembros del Tribunal Constitucional (art. 159.4 CE), podemos afirmar que si se realizase una nueva lectura general de este precepto, se deberían separar las cuestiones relativas a cada uno de los grupos integrantes de los diferentes órganos constitucionales. De esta manera, quedaría el artículo 98.3 específicamente dedicado a la regulación de los miembros (Presidente, Vicepresidente o Vicepresidentes si los hubiera, y Ministros) del Consejo de Ministros y el 98.4 recogería una remisión constitucional a una ley posterior para que regulase el estatuto general de los miembros del Gobierno, entendiendo éste en sentido amplio, y por tanto incluyendo el estatuto de los Secretarios de Estado, Subsecretarios, etc.

Por tanto, se puede defender una redacción del art.98.3 y 4 , en el sentido siguiente:

de los cargos de Presidente de la República, del Consejo de Ministros o Ministro de Justicia.

El Decreto Ley de 13 de mayo de 1955 en su artículo $3 .^{\circ}$ generaliza eșta prohibición a todos los Altos Cargos de la Administración.

12 EI R.D. 2102/83 fue derogado con posterioridad a la finalización de este trabajo, siendo sustituido por el R.D. 405/1992, de 25 de abril, que regula la cuestión de manera muy similar. 
3. Los miembros del Consejo de Ministros no podrán ejercer otras funciones representativas que las propias del mandato parlamentario, ni cualquier otra función pública que no derive de su cargo, ni actividad profesional o mercantil alguna.

4. La ley regulará el estatuto de los miembros del Gobierno. 